\title{
Role of Lymphatic Vessels in Tumor Immunity: Passive Conduits or Active Participants?
}

\author{
Amanda W. Lund • Melody A. Swartz
}

Received: 18 July 2010 / Accepted: 29 August 2010/Published online: 11 September 2010

(C) Springer Science+Business Media, LLC 2010

\begin{abstract}
Research in lymphatic biology and cancer immunology may soon intersect as emerging evidence implicates the lymphatics in the progression of chronic inflammation and autoimmunity as well as in tumor metastasis and immune escape. Like the blood vasculature, the lymphatic system comprises a highly dynamic conduit system that regulates fluid homeostasis, antigen transport and immune cell trafficking, which all play important roles in the progression and resolution of inflammation, autoimmune diseases, and cancer. This review presents emerging evidence that lymphatic vessels are active modulators of immunity, perhaps fine-tuning the response to adjust the balance between peripheral tolerance and immunity. This suggests that the tumor-associated lymphatic vessels and draining lymph node may be important in tumor immunity which in turn governs metastasis.
\end{abstract}

Keywords Lymph node $\cdot$ Lymphangiogenesis . Inflammation $\cdot$ Autoimmunity $\cdot$ Cancer
Abbreviations
APC antigen-presenting cell
CCL19/21 C-C chemokine ligand 19/21
CCR7 C-C chemokine receptor 7

\footnotetext{
A. W. Lund - M. A. Swartz

Institute of Bioengineering and Swiss Institute of Experimental

Cancer Research (ISREC),

École Polytechnique Fédérale de Lausanne,

Lausanne 1015, Switzerland

M. A. Swartz ( $\square)$

Institute of Bioengineering,

École Polytechnique Fédérale de Lausanne,

Station 15, Lausanne CH 1015, Switzerland

e-mail: melody.swartz@epfl.ch
}

$\begin{array}{ll}\text { CXCL13 } & \text { C-X-C Chemokine ligand } 13 \\ \mathrm{DC} & \text { dendritic cell } \\ \text { FRC } & \text { fibroblastic reticular cell } \\ \mathrm{LN} & \text { lymph node } \\ \text { TLO } & \text { tertiary lymphoid organ } \\ \mathrm{T}_{\text {Reg }} \text { cell } & \text { regulatory T cell } \\ \text { VEGF } & \text { vascular endothelial growth factor }\end{array}$

\section{Introduction}

The lymphatic system is an extensive network of vessels that function to regulate tissue fluid homeostasis, immune cell trafficking and transport of dietary lipids [1]. Lymphatic vessels bring peripheral antigens and antigen presenting cells (APCs) like dendritic cells (DCs) to lymph nodes (LNs) where adaptive immunity can be initiated. This occurs either from lymph-borne antigen capture by B cells and lymph node resident APCs [2-4], or by the more classical route of peripherally-activated DC migration to the $\mathrm{LN}$ and activation of resident $\mathrm{T}$ cells [5]. Lymph nodes are also important centers for the maintenance of tolerance to self-antigens [4, 6-9].

For such functions, lymphatic vessels are traditionally considered to be passive conduits that deliver peripheral antigens and cells to the LN. However, new evidence is emerging that lymphatic vessels play very active roles in directing the initial steps of the immune response and sensing and responding to subtle changes in the peripheral microenvironment that may in turn alter $\mathrm{LN}$ functions in immunity and tolerance. Furthermore, evidence is emerging that indicates a coupling between lymphatic vessel function and $\mathrm{LN}$ function in tolerance and immunity. 
Adult lymphangiogenesis occurs during inflammation and wound healing $[1,10]$, but is also strongly associated with chronic inflammation, autoimmunity, and allograft rejection [11-16] as well as with tumor invasion and metastasis when initiated both around the tumor and in the draining LN [17-21]. These are all associated with different immunological outcomes: from Th1 and Th2 inflammatory responses to immune escape and tolerance. Thus, the specific and functional roles of lymphatics and lymphangiogenesis in regulating the host immune response remain obscure.

Lymphatics pervade the interlobular connective tissue of the mammary gland during lactating periods and drain into collecting lymphatics, which run along mammary ducts [22-24]. During lactation the number of interlobular lymphatics and interendothelial gaps increase to promote transport [22]. Additionally, the lymphatics are the key route for LN and distal metastases, have altered flow patterns during cancer and increased levels of vascular endothelial growth factor C (VEGF-C) and its receptor VEGFR-3 lead to poor overall prognosis [25-27]. In this way, the lymphatics are active components of both normal tissue function and disease in the mammary gland; however, little is known about the dynamics of their function in this microenvironment.

In this review, we discuss recent insights into the immunological relationships between lymphatic vessels, their functional regulation, and the draining $\mathrm{LN}$, with broad application to the biology of the mammary gland and tumors. We introduce new perspectives on how lymphatic vessels may help fine-tune the immune response, and present new perspectives on the potential role of tumorassociated lymphatics on tumor immunity and tolerance.

\section{Lymphatic Physiology and Neogenesis}

Lymphatic vessels are found in all vascularized tissues, with the exception of bone marrow and the central nervous system. Interstitial fluid drains into lymphatic capillaries (also known as initial lymphatics and terminal lymphatics) that are blind-ended vessels with a discontinuous basement membrane that lack pericytes. The interendothelial adhesions are maintained by discontinuous, "button-like" junctions serving to both freely drain interstitial proteins and also facilitate immune cell transmigration [28-31]. These overlapping cell-cell junctions serve as primary valves to prevent backflow from the lymphatic vessel into the tissue [32] and secondary valves prevent backflow within the vessel [33]. These capillaries drain into precollecting and collecting vessels that have continuous, "zipper-like" interendothelial junctions [30] and are surrounded by smooth muscle. Collecting vessels are organized into contractile segments called lymphangions, separated by bileaflet valves, that create the driving force for unidirectional lymph propulsion [30, 31, 34-36]. Collecting lymphatic vessels that carry lymph to and from the lymph nodes are referred to as afferent and efferent lymphatic vessels, respectively. Lymph typically passes through several lymph nodes before collecting in the thoracic duct where it is returned to the blood via connection with the great veins of the neck. Thus, the lymphatic vascular hierarchy is adapted to specifically promote the entrance of APCs and antigen-rich lymph into blind-ended capillaries and drive continuous, one-way movement of antigen and cells towards the draining LNs.

The initial lymphatic vasculature can be subdivided into the initial lymphatic capillaries and the precollectors, which link the capillaries to the collecting vessels. Interestingly, these segments express different levels of podoplanin that is associated with differential chemokine expression [37]. Lymphatic capillaries express high levels of podoplanin as well as the chemokine (C-C motif) ligand 21 (CCL21), which may bind podoplanin and which attracts activated $\left(\mathrm{CCR}^{+}\right)$antigen-presenting cells; the coexpression of podoplanin and CCL21 may have important implications for their specific function. On the other hand, precollectors express lower levels of podoplanin and secrete CCL27, which recruits memory $\mathrm{CCR} 10^{+} \mathrm{T}$ cells. In this way, different immune cell types enter lymphatic capillaries at specialized sites [37].

Enhanced vascular permeability and leakage is observed during tissue injury and certain types of inflammation, thereby increasing the fluid load on the draining lymphatics. Both the increase of interstitial pressure and flow, as well as the change in cytokines and inflammatory mediators, stand to influence this drainage, yet the latter is only beginning to be explored [38, 39]. Transmural flow itself can activate the lymphatic endothelium, increasing fluid and solute permeability and uptake as well as upregulating adhesion molecules required for immune cell transmigration [40]. These changes can be observed at very low fluid flows of $0.1-1 \mathrm{dyn} / \mathrm{cm}^{2}$, which is well-correlated to the slow interstitial flows observed in normal and inflamed tissue. Flow also enhances the expression of CCL21 both in lymphatic vessels [40] and in the lymph node [41]. In addition to activating lymphatic endothelium, lymphatic drainage also facilitates interstitial flow, directed towards the lymphatics. This directional flow promotes cell homing by biasing pericellular autocrine chemokine gradients thereby driving DC and tumor cell chemotaxis towards draining lymphatics [42, 43]. Thus, lymphatics are dynamic sensors of acute biomechanical changes that accompany the onset of tissue injury and inflammation and are inherently coupled to immune cell trafficking and antigen transport to and within the draining LN [44]. 
In addition to regulating function, fluid flow is also an important regulator of lymphatic morphogenesis or lymphangiogenesis, and has been shown to drive lymphatic capillary organization in dermal wound healing models [45, 46] as well as in vitro culture models [47-49]. Without flow, as in the case of lymphedema, lymphatic endothelium becomes hyperplastic (i.e. the diameter of lymphatic capillaries increases while their density remains unchanged) [50]. In general, lymphatic hyperplasia and lymphangiogenesis have not been carefully distinguished in the literature, even though these are likely to have different effects on tissue fluid clearance and drainage to the lymph node[ $1,28,51]$. Molecular mediators of lymphangiogenesis are well described in several recent reviews $[1,52,53]$ and will not be discussed in detail here. Briefly, lymphangiogenesis is mainly associated with vascular endothelial growth factor (VEGF)-C and -D, VEGFR-3 ligands, and contribution from other factors such as VEGF-A and coreceptors VEGFR-2 and neuropilin-2 have also been reported. Blocking VEGFR-3 in adult mice, alone or in combination with VEGFR-2 blockade, can specifically and completely inhibit lymphangiogenesis $[1,52,54,55]$, and has been a useful tool to determine the effects of lymphangiogenesis on graft rejection, autoimmunity, and cancer metastasis, as described later.

\section{Secondary Lymphoid Organs}

Transport of lymph to the draining LN is achieved in such a way as to optimize the delivery of pathogenic signals, antigens, and immune cells to promote antigen capture by $\mathrm{B}$ cells and DCs, and facilitate $\mathrm{T}$ cell education and priming [5, 51] (Fig. 1). Lymph enters the subcapsular sinus of the draining LN through afferent vessels and moves through the medullary sinus via a network of conduits, formed by follicular dendritic cells in the B cell zone and fibroblastic reticular cells (FRCs) in the T cell zone, prior to leaving the LN via efferent vessels [56, 57]. FRCs express podoplanin (gp38) and the CCR7 ligands, CCL21 and CCL19; CCL21 is readily immobilized into the proteoglycan components of the extracellular matrix to form solid-phase gradients upon which DCs and T cells migrate $[58,59]$.

FRCs bundle collagen fibers to form $10-20 \mu \mathrm{m}$ conduits that are in close proximity to an extensive network of DCs that directly sample antigen carried by the lymph for presentation to naïve $\mathrm{T}$ cells [60]. These conduits direct antigen and APCs towards high endothelial venules, a specialized vasculature that promotes the delivery of naïve $\mathrm{T}$ cells into the $\mathrm{LN}$. This site of interaction between extravasating lymphocytes and mature APCs is important for initiating T cell-specific immunity.
Fluid flow through this FRC/collagen network is required for proper 3D organization in vitro [41]. During acute inflammation or injury, lymph flow through the LN can be increased, dramatically enhancing CCL21 expression by FRCs [41] and accelerating the rate of APC and antigen delivery to the draining LN. Occlusion of the afferent lymphatic vessel, and consequent blockage of lymph flow into the $\mathrm{LN}$, results in alterations in high endothelial venules (flattening of lumen and decreased luminal peripheral node addressin expression) and a subsequent decrease in lymphocyte extravasation from the blood [61]. Thus, the drainage function of peripheral lymphatic vessels is critical not only for peripheral tissue homeostasis and fluid balance, but also for proper LN organization and function.

Lymph node development and organization is accomplished mainly by the differential expression of CCL21 and CXCL13 in the T and B cell zones, respectively [62-65]. CCL21 and CXCL13 are ligands for CCR7 and CXCR5 (expressed by B cells), respectively, and are secreted by mesenchymal cells in the early developing lymph node to drive lymphoid tissue formation through the attraction of $\mathrm{CD} 3 \varepsilon^{-} \mathrm{CD} 4^{+} \mathrm{IL}-7 \mathrm{R} \alpha^{\text {hi }} \mathrm{CCR}^{+}$and $\mathrm{CXCR}^{+}$lymphoid tissue inducer cells $[62,66]$. The $3 \mathrm{D}$ organization of the lymph node is also driven and maintained by these cytokines; FRCs of the T cell zone express CCL21 and CCL19, which guide the interactions between CCR $7^{+} \mathrm{T}$ cells and APCs, while follicular dendritic cells express CXCL13 to define and maintain zones of $\mathrm{CXCR} 5^{+} \mathrm{B}$ cells [67]. Mice deficient in both CXCR5 and CCR7 lack peripheral lymph nodes and exhibit abnormal architectures of the deep mesenteric lymph nodes and the spleen [66].

$\mathrm{LN}$ architecture is conserved across anatomical locations, but the immune responses induced in different LNs can differ [68] as the homing capacity of T cells is dependent upon the draining $\mathrm{LN}$ in which they are activated. For example, $T$ cells activated in the mesenteric lymph node express CCR9 and $\alpha_{4} \beta_{7}$ integrin and specifically home to the intestinal mucosa, whereas $T$ cells activated by peripheral LN home to skin [68]. This specificity is unique to the LN stroma and cannot be replicated by resident DCs; for example, DCs extracted from the mesenteric $\mathrm{LN}$ can stimulate T cells in vitro to home to the gut, but when injected subcutaneously they instead direct $\mathrm{T}$ cell homing to the skin [69]. Therefore, the induction of specific and directed immune responses is attributable to innate functions of the LN stromal compartments.

\section{Lymphoid Organs in Peripheral Tolerance}

The compartmentalized expression of CCL19 and CCL21 in the paracortex of the $\mathrm{LN}$ is not only critical for the 


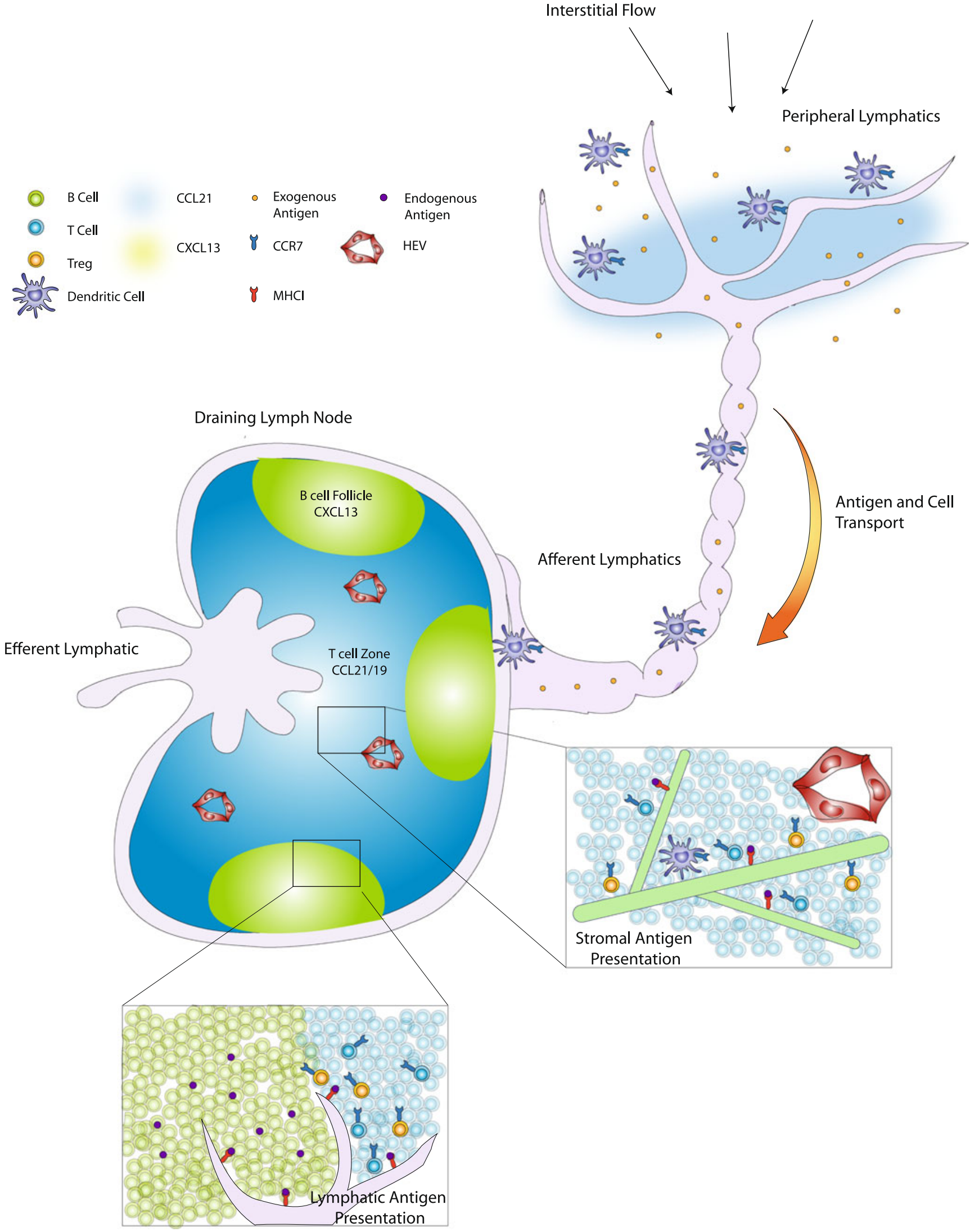


4 Figure 1 Lymphatic-mediated antigen and cell transport to the draining lymph node primes the resident stroma and lymphatic endothelial cells for antigen presentation. Peripheral lymphatics collect soluble antigen and secrete CCL21 to attract activated dendritic cells (DCs), which use lymphatics for transport to the draining lymph node (LN). Lymph is drained through the subcapsular lymphatics and through the fibroblastic reticular cell conduit network bathing the $\mathrm{LN}$ in antigens and peripherally expressed inflammatory cytokines. Lymph exits the LN through efferent lymphatic vessels and passes through several lymph nodes prior to recycling back into the blood vasculature. Peripherally activated DCs migrate along the $\mathrm{CCL} 21^{+} \mathrm{gp} 38^{+}$stromal conduit networks to educate naïve CCR $7^{+} \mathrm{T}$ cells. Resident immature DCs also lie close to this stromal network and sample antigen draining through the $\mathrm{LN}$. CCR $7^{+}$regulatory $\mathrm{T}$ $\left(\mathrm{T}_{\mathrm{Reg}}\right)$ cells similarly require this $\mathrm{CCL} 21^{+}$stroma to migrate through the $\mathrm{LN}$ and become activated while efficient $\mathrm{CD} 8^{+} \mathrm{T}$ cell responses can occur outside of the LN. FRCs endogenously express peripheral antigen on MHC class I molecules to promote tolerance through $\mathrm{CD} 8^{+} \mathrm{T}$ cell deletion. Similarly, CCL $21^{+}$gp $38^{+} \mathrm{LYVE} 1^{+}$lymphatic endothelial cells express endogenous antigen for $\mathrm{T}$ cell deletion. Thus, the tolerance-maintaining functions of the draining lymph node are dependent upon peripheral tissue drainage and local nonhematopoeitic cell populations

correct positioning of APCs with T cells, but also required for its tolerance-maintaining functions [62]. Mice lacking CCR7 show impaired ability to maintain tolerance to peripheral antigens as they develop signs of autoimmunity $[70,71]$ : they exhibit lymphocyte infiltration in peripheral organs, elevated levels of circulating antibodies towards tissue-specific antigens, IgG deposition around the renal glomeruli, and increased susceptibility to inducible diabetes, and they can spontaneously develop chronic autoimmune renal disease [70]. These mice, as well as those lacking CCL19 and CCL21 (plt mice), which lack recognizable $\mathrm{T}$ cells zones within all LNs [72-76], can still mount strong cellular immune responses [6].

This is consistent with the mounting evidence that although B cell responses require their residence in functional lymph nodes, $\mathrm{T}$ cell immunity apparently does not, and $\mathrm{T}$ cells can be activated in the spleen or even liver when lymph nodes are absent or dysfunctional (reviewed in [77]). For this reason, proper LN function may be more indispensible for peripheral tolerance than cellular immunity. Unlike $\mathrm{CD} 8^{+}$effector cells, FoxP $3^{+} \mathrm{T}_{\text {Reg }}$ cells require LN occupancy and CCR7 signaling for their activation and function [78-80]. $\mathrm{T}_{\text {Reg }}$ cells sequentially migrate between peripheral tissues and LNs to both inhibit DC migration from the periphery as well as prevent effector $\mathrm{T}$ cell migration, activation and proliferation [81]. In the inflamed peripheral tissues, $\mathrm{T}_{\text {Reg }}$ cells are activated, secrete transforming growth factor $\beta$ and interleukin 10 (IL-10) and then migrate to the draining LN in a CCR7-dependent manner [81]. Upon reaching the $\mathrm{LN}, \mathrm{T}_{\mathrm{Reg}}$ cells preferentially migrate to the paracortex where they interact with $\mathrm{CD} 8 \alpha^{+}$DCs and tissue derived $\mathrm{CD} 11 \mathrm{~b}^{-} \mathrm{CD} 8 \alpha^{-}$DCs [82]. $\mathrm{CD} 8 \alpha^{+}$DCs, which are critical for peripheral cross-tolerance to soluble antigen, cluster with $\mathrm{T}_{\text {Reg }}$ cells in the paracortical area of the $\mathrm{LN}$ $[60,82]$. The role of CCR7 in coordinating these interactions is again highlighted by studies in $\mathrm{CCR} 7^{-/}$mice, which exhibit impaired $\mathrm{T}_{\text {Reg }}$ cell positioning and loss of their ability to promote tolerance and prevent autoimmune pathologies $[83,84]$. In addition, both $\mathrm{CCR} 7^{+} \mathrm{MHCII}{ }^{+} \mathrm{CD} 86^{+} \mathrm{DCs}$ as well as $\mathrm{CCR} 7^{+} \mathrm{T}_{\mathrm{Reg}}$ cells are required for the optimal induction of a tolerance response, implying that CCR7 critically functions to bring these two cell types together within the context of the LN stroma [84].

The tolerance-maintaining functions of the $\mathrm{LN}$ are also facilitated by stromal cells, which express adhesion molecules and chemokines that shape cell migration routes, fluid distribution and tissue-specific immune responses (Fig. 1). In LN transplantation experiments, where the hematopoietic cells of the LN were completely replaced by host cells while the stromal compartments remained donor derived, the specific $\mathrm{T}$ cell homing responses induced were those of the original location, rather than the transplanted location $[9,69,85]$. Additionally, while removal of the cervical LN blocked the induction of musosal tolerance, rescue could be achieved by transplanting a donor cervical $\mathrm{LN}$ but not mesenteric or peripheral LNs [86]. The stromal cells maintain peripheral tolerance functions through the constitutive expression of relevant peripheral tissue antigens presented on MHC class I molecules for $\mathrm{CD}^{+} \mathrm{T}$ cell deletion [87]. This mirrors the central tolerance maintaining functions of medullary thymic epithelial cells, which exhibit promiscuous gene expression and thereby express antigen from all tissues of the body to deactivate self-reactive $\mathrm{T}$ cells through deletion (recessive tolerance) and $\mathrm{T}_{\text {Reg }}$ cell induction (dominant tolerance) [88]. Thus, the LN stromal cells hold intrinsic, tissue-specific capabilities that likely play similar roles in peripheral tolerance as thymic epithelial cells play in central tolerance [7, 89-91].

Recently, it has been shown that lymphatic endothelial cells in the LN also present endogenous antigen on MHC class I molecules (Fig. 1), and this tolerance function is independent of the autoimmune regulator Aire [8]. Specifically, peripheral LNs draining the skin were shown to express the antigens tyrosinase and melanocytic differentiation antigen, leading to deletional tolerance of autoreactive $\mathrm{CD}^{+} \mathrm{T}$ cells. Thus, lymphatic vessels themselves are likely to be important players in maintaining tolerance to selfantigens, particularly after tissue injury. This is achieved both through their control over peripheral drainage, which provides constant antigen sampling to the largely immature APC population that resides in the draining LN [44], as well as their ability to directly present endogenous antigens for deletional tolerance [8].

Together, these recent findings provide a new perspective on the role of LN lymphangiogenesis, which occurs in 
LNs draining inflamed [14, 16, 92], immunized [14, 93], and tumor-bearing tissues prior to metastasis $[18,19]$. LN lymphangiogenesis leads to increased DC trafficking from the periphery and is dependent on LN resident B cells [14]. Both VEGF-C and VEGF-A promote LN lymphangiogenesis when secreted by lymphoid tissue inducer cells and B cells respectively [92, 94]. In addition, VEGF-A produced by chronically-inflamed tissue induces lymphangiogenesis in the draining LN which, taken with lymphangiogenesis at the periphery, may enhance the immune response through trafficking of macrophages and dendritic cells $[14,16]$. The lymph node itself, therefore, acts as an early downstream signal to promote peripheral changes in immune cell trafficking and lymphatic expansion. In light of the new tolerance-maintaining functions of LN lymphatic endothelium described above [8], it is intriguing to consider the possibility that lymphangiogenesis in the LN draining inflamed or tumor-bearing tissue might contribute to tumor tolerance, if these newly formed lymphatic vessels also express antigen on MHC class I molecules.

\section{Tertiary Lymphoid Organs}

While secondary lymphoid tissues can be remodeled during acute inflammation to alter lymph flow, lymph content, blood flow and high endothelial cell differentiation $[63,95]$, de novo lymphoid tissue formation occurs during states of chronic inflammation. These tertiary lymphoid organs (TLOs) are characterized by lymphocyte infiltrates, B cell follicles and defective fluid drainage [96]. TLOs have been observed in a variety of autoimmune disorders including autoimmune thyroid disease, rheumatoid arthritis and Crohn's disease [62, 97] (Fig. 2). The defining characteristic of autoimmune-related TLOs are their germinal centers that produce auto-antibodies [96]. Furthermore, as B cells stimulate lymphangiogenesis (mentioned earlier), such TLOs are often also associated with lymphangiogenesis. In renal interstitial disease, for example, lymphangiogenesis is stimulated around the newly formed follicles and contributes to the formation of intrarenal lymphoid follicle-like structures [98]. The crosstalk between developing $\mathrm{B}$ cell follicles and the lymphangiogenesis that it induces may play an important role in promoting mature follicle formation and remains an interesting question to address.

Just as with LNs, TLO formation can be induced through overexpression of CCL21, CCL19 and CXCL13 in a tissuespecific manner $[65,99,100]$. Furthermore, they may accumulate antigen and APCs, bypassing the LN and therefore restricting normal LN function [62, 101]. Such circumvention of the normal LN may prevent the induction of an appropriate immune response to foreign antigen or, since the LN has important tolerance-maintaining functions described earlier, result in autoimmunity (Fig. 2). Indeed, the role of peripheral TLO neogenesis as either a pathology to target therapeutically or an important protective mechanism of immunity remains controversial. For example, while TLOs have been shown to sequester pathogen and prevent its systemic spread during bacterial infection, they may also contribute to lymphoma development, prion accumulation and autoimmunity [62]. Importantly, the way that TLOs affect lymphatic drainage to bypass relevant LN and thereby circumvent their tolerance-maintaining function is poorly understood. Further research into this question will likely lead to therapeutic strategies for autoimmunity and has potential to strongly impact cancer research, where increased lymphatic drainage seems to promote tumor growth (implying an inhibition of antitumor immunity).

\section{Pathological Lymphangiogenesis}

\section{Chronic Inflammation}

Lymphangiogenesis has long been associated with chronic inflammation. Inflammatory lymphangiogenesis can be driven by immune cell-released VEGF-C, and inflammatory stimuli promote lymphatic endothelial cell susceptibility to VEGF-C through the upregulation of VEGFR3 and Prox-1 [102]. Tissue necrosis factor $\alpha$, as well as newly recruited macrophages and granulocytes, can enhance the local expression of VEGF-C within inflamed tissue to promote lymphangiogenesis [103]. Another pro-inflammatory cytokine, interleukin (IL)-1 $\beta$, promotes lymphangiogenesis by stimulating VEGF-A, VEGF-C, and VEGF-D [104]. In addition to the inflamed tissue, lymphangiogenesis also occurs in the LN draining this tissue $[14,16,51]$.

Inflammation-associated lymphangiogenesis may be important for the clearance of immune infiltrates; for example, inhibiting lymphangiogenesis by VEGFR-3 blockage exacerbated pulmonary edema caused by chronic myocplasma pulmonis infection and prevented the resolution of inflammation [103]. On the other hand, in cases of chronic inflammation, the extensive lymphatic remodeling that occurs can have detrimental affects on normal immune function $[1,105,106]$. Hyperplastic lymphatics in chronic diseases such as psoriasis, inflammatory bowel disease, chronically-inflamed skin disease and rheumatoid arthritis have negative implications for disease resolution. For these conditions, treatment with anti-VEGF antibodies can, in some cases, promote disease resolution [106-109]. Furthermore, while vascular angiogenesis can be reversed in chronic inflammation, lymphangiogenic structures seem to persist $[103,110]$. This implies that while the blood 


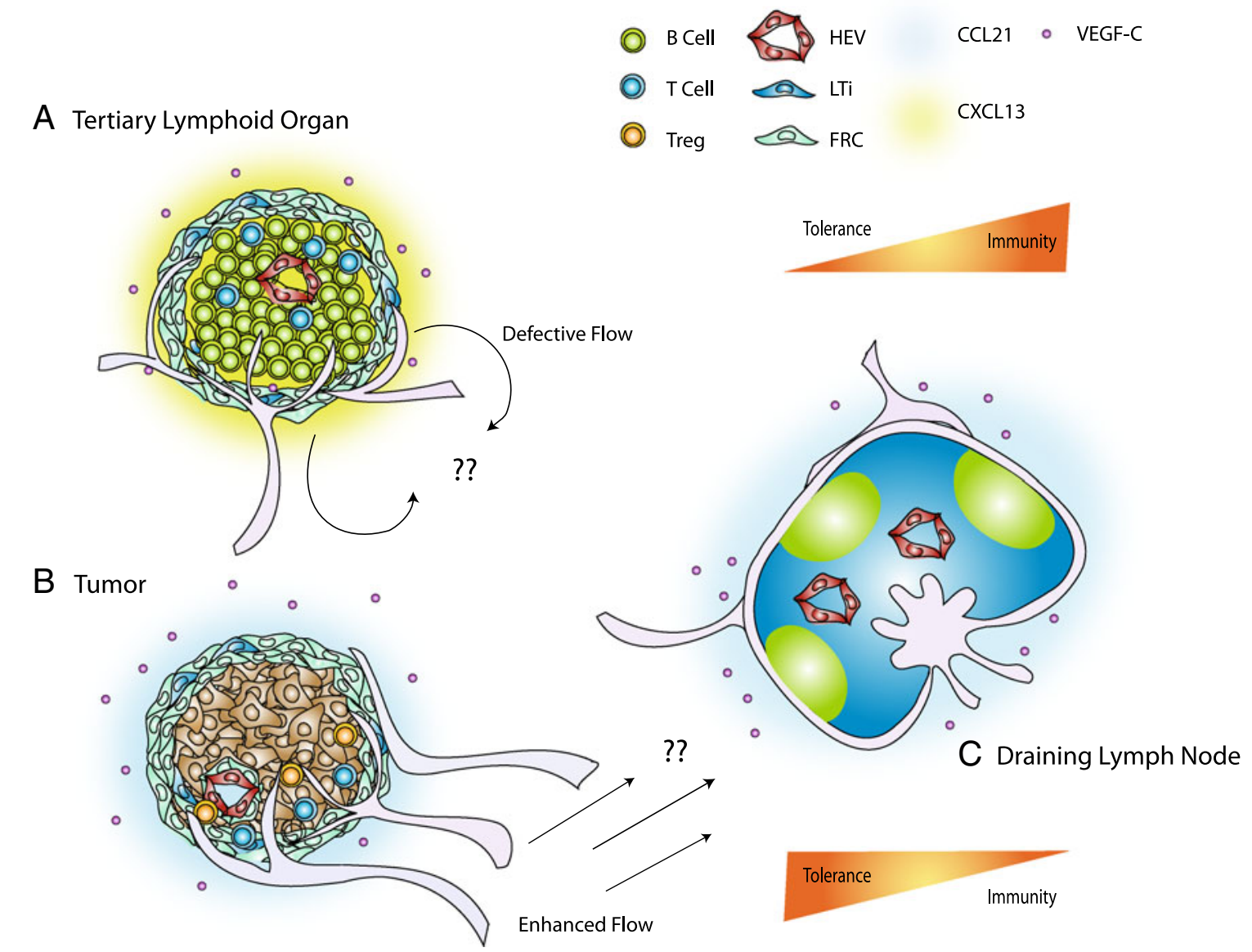

Figure 2 Peripheral lymphoid organogenesis alters fluid flow to the draining lymph node and can shift the balance between immunity and tolerance. a Tertiary lymphoid organs (TLOs) can develop in response to chronic inflammation and is characterized by immune cell infiltrates, lymphangiogenesis and altered fluid flow patterns. b Additionally, melanomas can develop stromal features reminiscent of the paracortex of the lymph node. Both the lymphoid stromal transformation that occurs in the peritumoral space as well as that surrounding immune cell infiltrates in TLOs exhibit a gp $38^{+}$ER-TR $7^{+}$ stromal network, high endothelial venule-like $\mathrm{PNAd}^{+} \mathrm{CD} 31^{+}$blood vessels, and gp $38^{+} \mathrm{LYVE}^{+}$lymphatics. A distinguishing feature between the two structures is the absence of B cell follicles and

vasculature requires both growth and maintenance cues the lymphatic vasculature may not.

\section{Chronic Graft Rejection}

Dysfunctional lymphatics and changes in lymphatic drainage and immune cell trafficking can initiate organ-specific autoimmunity. Chronic graft rejection correlates with increased lymphatic density within the grafted tissue and these lymphatic vessels are significantly enriched in areas of immune cell infiltrates $[12,111]$. In models of corneal implantation, lymphatic ingrowth is significantly associated with poor graft survival and rejection [11, 112-114].
CXCL13 within the melanoma environment, which is predominated by $\mathrm{T}$ cells and CCL21. B cell germinal centers within TLOs are largely responsible for autoantibody production and autoimmunity in chronic inflammation and graft rejection. Additionally, it has been suggested that TLO-associated lymphatic vessels reroute lymph flow from the draining lymph node [101], whereas the enhanced flow that results from lymphangiogenesis in the tumor environment may promote constant soluble antigen presentation that may be a requirement for tolerance maintenance by the draining lymph node. The tolerance-maintaining functions of the draining LN are thereby critically linked to the functionality of peripheral lymphatics, the pattern of drainage and inflammatory state of the tissue
Blocking lymphangiogenesis using anti-VEGFR-3 antibodies promote the acceptance of grafted tissue [104], although it is difficult to generalize this to other tissues that are normally not alymphatic like the cornea. For bone implants, lymphangiogenesis at the bone-implant interface can promote host destruction of the tissue as well as the formation of distal granulomas, neoplasia and lymphoma [15].

\section{Cancer}

Lymphatic dissemination of solid tumors involves the directional homing of tumor cells to primed and expanding 
lymphatic vessels $[1,115]$. Expression of the lymphangiogenic factors VEGF-C and -D is significantly correlated with lymphangiogenesis (tumoral and nodal) and LN metastasis in a variety of primary tumors including thyroid, prostate, gastric, colorectal, lung and breast in both human and animal models $[17,20,116,117]$. Although VEGF-C is well-correlated with cancer metastasis, the requirement for tumor lymphangiogenesis is controversial, and there is evidence that VEGF-C can promote metastasis in the absence of tumor lymphangiogenesis [118-123]. VEGF-C can also attract macrophages [124] that can alter the tumor microenvironment to promote invasion. Furthermore, some tumor cells also express VEGFR-3 and thus may benefit from autocrine signaling of VEGF-C or -D [121, 125-129]. Such autocrine signaling could help tumor cells home to lymphatics by guiding them in the direction of flow [42]. Finally, in addition to driving lymphangiogenesis, tumor VEGF-C also upregulates the expression of CCL21 by lymphatic endothelium to further promote lymphatic invasion via CCR7 expression [121]. Clearly, VEGF-C in the tumor microenvironment promotes tumor progression and invasion, but since VEGF-C can play so many different roles in the tumor microenvironment it has been difficult to dissect out the specific contributions of tumor lymphangiogenesis to these processes.

Tumor association with the lymphatic system may not only affect the local microenvironment, but also the host immune response to the tumor. As mentioned, VEGF-C and CCL21 between tumors and lymphatic endothelium display significant cross-talk [121], and the upregulation of CCL21 in the tumor microenvironment may impart certain features of lymphoid neogenesis to the tumor. B16-F10 murine melanoma cells, like many other cancer cells, express low levels of CCL21 [42]. When these cells were engineered to knockdown endogenous CCL21, they were rejected (as evidenced by tumor-antigen specific $\mathrm{CD} 8^{+} \mathrm{T}$ cells and tumor regression), while control and CCL21-overexpressing tumors recruited lymphoid tissue inducer cells, formed lymphoidlike stroma, and were infiltrated with $\mathrm{T}_{\text {Reg }}$ cells [130]. Unlike in autoimmune-associated TLOs, these tumors did not express CXCL13 or generate B cell follicles, but mimicked features of the T cell zone stroma of the $\mathrm{LN}$, which are again important in peripheral tolerance. Therefore, while the LN contains many different features that collectively orchestrate an immune response, it is likely that TLOs and tumors only recapitulate certain features of the $\mathrm{LN}$-germinal center formation and paracortical stromal mimicry, respectively-to skew the immune response towards one extreme (autoantibody formation, as in the case of most TLOs) or the other (immunological tolerance, as in the case of tumors).

These recent findings raise the interesting possibility that peritumoral lymphangiogenesis may affect host immunity (Fig. 2). First, as mentioned, VEGF-C drives an upregula- tion of CCL21 in the local lymphatic vessels [121], and this may drive stromal changes that promote a switch from immunogenic to $\mathrm{T}_{\mathrm{Reg}}$ cell education [130]. Second, the lymphatic endothelium itself may express tumor antigen to delete $\mathrm{CD}^{+}$effector cells, as it does in the lymph node with endogenous peripheral tissue antigen [8]. Finally, the increased drainage it induces to the draining LN [131-133] could activate the tolerance-maintaining functions of the lymph node by upregulating CCL21 [41] and bathing the $\mathrm{LN}$ with tumor antigen.

\section{Future Directions}

Lymphatic vessels and lymphatic drainage are emerging players in our understanding of the balance between immunity and tolerance. The presence of lymphatics draining mammary tissues and their active regulation during lactation, infection and cancer highlights their importance in mammary gland biology and cancer; however, few studies have addressed this specific topic in breast tissue. Additionally, the extent to which lymphatic vessels participate in programming the immune responsefor example, by modulating lymph flow and immune cell trafficking, by expressing endogenous antigen for $\mathrm{T}$ cell modulation, or by adapting various immune cell functionsremains incompletely understood.

While individual pieces of the puzzle have been identified, the overall picture of lymphatic function in immunity is only beginning to emerge. Recent evidence demonstrates that LN-resident lymphatic endothelium can present endogenous antigens, yet its overall importance in maintaining peripheral tolerance to those tissues that it specifically drains is unknown; whether this mechanism can extend to peripheral lymphatics such as those that are expanded in the tumor microenvironment remains an interesting question that is yet to be answered. Additionally, recent work demonstrates the importance of lipid transport from perilymphatic adipose depots by trafficking APCs, thereby modulating their ability to present antigen and stimulate and immune response [134]. The relevance of the dynamic adipose microenvironment in the breast to lymphatic function and immunity remains an open question.

In general, lymphatic sensitivity to the dynamic microenvironment under steady state and diseased conditions remains poorly understood. Much more research on the interface between lymphatic biology and immunology is needed to elucidate the importance of this underappreciated component of immunity. In particular, we believe that expounding the differences between lymphangiogenesis and TLO formation (or lymphoid stromal mimicry) in cancer vs. autoimmunity will provide novel therapeutic targets for cancer immunotherapy. 


\section{References}

1. Tammela T, Alitalo K. Lymphangiogenesis: molecular mechanisms and future promise. Cell. 2010;140(4):460-76.

2. Itano AA, McSorley SJ, Reinhardt RL, Ehst BD, Ingulli E, Rudensky AY, et al. Distinct dendritic cell populations sequentially present antigen to CD4 $\mathrm{T}$ cells and stimulate different aspects of cell-mediated immunity. Immunity. 2003;19(1):47-57.

3. Pape KA, Catron DM, Itano AA, Jenkins MK. The humoral immune response is initiated in lymph nodes by B cells that acquire soluble antigen directly in the follicles. Immunity. 2007;26(4):491-502.

4. Wilson NS, El-Sukkari D, Belz GT, Smith CM, Steptoe RJ, Heath WR, et al. Most lymphoid organ dendritic cell types are phenotypically and functionally immature. Blood. 2003;102 (6):2187-94.

5. Randolph GJ, Angeli V, Swartz MA. Dendritic-cell trafficking to lymph nodes through lymphatic vessels. Nat Rev Immunol. 2005;5(8):617-28.

6. Förster R, Davalos-Misslitz A, Rot A. CCR7 and its ligands: balancing immunity and tolerance. Nat Rev Immunol. 2008;8 (5):362-71.

7. Reynoso ED, Lee JW, Turley SJ. Peripheral tolerance induction by lymph node stroma. Adv Exp Med Biol. 2009;633:113-27.

8. Cohen JN, Guidi CJ, Tewalt EF, Qiao H, Rouhani SJ, Ruddell A, et al. Lymph node-resident lymphatic endothelial cells mediate peripheral tolerance via Aire-independent direct antigen presentation. J Exp Med. 2010;207(4):681-8.

9. Kraal G, Samsom JN, Mebius RE. The importance of regional lymph nodes for mucosal tolerance. Immunol Rev. 2006;213:119-30.

10. Ji RC. Lymphatic endothelial cells, inflammatory lymphangiogenesis, and prospective players. Curr Med Chem. 2007;14 (22):2359-68.

11. Patel SP, Dana R. Corneal lymphangiogenesis: implications in immunity. Semin Ophthalmol. 2009;24(3):135-8.

12. Kerjaschki D, Regele HM, Moosberger I, Nagy-Bojarski K, Watschinger B, Soleiman A, et al. Lymphatic neoangiogenesis in human kidney transplants is associated with immunologically active lymphocytic infiltrates. J Am Soc Nephrol. 2004;15 (3):603-12.

13. Nasr IW, Reel M, Oberbarnscheidt MH, Mounzer RH, Baddoura FK, Ruddle NH, et al. Tertiary lymphoid tissues generate effector and memory $\mathrm{T}$ cells that lead to allograft rejection. Am J Transplant. 2007;7(5):1071-9.

14. Angeli V, Ginhoux F, Llodra J, Quemeneur L, Frenette PS, Skobe M, et al. B cell-driven lymphangiogenesis in inflamed lymph nodes enhances dendritic cell mobilization. Immunity. 2006;24(2):203-15.

15. Jell G, Kerjaschki D, Revell P, Al-Saffar N. Lymphangiogenesis in the bone-implant interface of orthopedic implants: importance and consequence. J Biomed Mater Res A. 2006;77A(1):119-27.

16. Halin C, Tobler NE, Vigl B, Brown LF, Detmar M. VEGF-A produced by chronically inflamed tissue induces lymphangiogenesis in draining lymph nodes. Blood. 2007;110(9):3158-67.

17. Achen MG, McColl BK, Stacker SA. Focus on lymphangiogenesis in tumor metastasis. Cancer Cell. 2005;7(2):121-7.

18. Hirakawa S, Brown LF, Kodama S, Paavonen K, Alitalo K, Detmar M. VEGF-C-induced lymphangiogenesis in sentinel lymph nodes promotes tumor metastasis to distant sites. Blood. 2007;109(3):1010-7.

19. Hirakawa S, Detmar M, Kerjaschki D, Nagamatsu S, Matsuo $\mathrm{K}$, Tanemura A, et al. Nodal lymphangiogenesis and metastasis role of tumor-induced lymphatic vessel activation in extramammary paget's disease. Am J Pathol. 2009;175(5): 2235-48.

20. Skobe M, Hamberg LM, Hawighorst T, Schirner M, Wolf GL, Alitalo $\mathrm{K}$, et al. Concurrent induction of lymphangiogenesis, angiogenesis, and macrophage recruitment by vascular endothelial growth factor-C in melanoma. Am J Pathol. 2001;159 (3):893-903.

21. Liersch R, Biermann C, Mesters RM, Berdel WE. Lymphangiogenesis in cancer: current perspectives. Recent Results Cancer Res. 2010;180:115-35.

22. Ohtani O, Shao XJ, Saitoh M, Ohtani Y. Lymphatics of the rat mammary gland during virgin, pregnant, lactating and post-weaning periods. Ital J Anat Embryol. 1998;103(4 Suppl 1):335-42.

23. Raharison F, Sautet J. The topography of the lymph vessels of mammary glands in female cats. Anat Histol Embryol. 2007;36 (6):442-52.

24. Heath TJ, Kerlin RL. Lymph drainage from the mammary gland in sheep. J Anat. 1986;144:61-70.

25. Mylona E, Alexandrou P, Mpakali A, Giannopoulou I, Liapis G, Markaki S, et al. Clinicopathological and prognostic significance of vascular endothelial growth factors (VEGF)-C and -D and VEGF receptor 3 in invasive breast carcinoma. Eur J Surg Oncol. 2007;33(3):294-300.

26. Pereira CT, Rahal SC, de Carvalho Balieiro JC, Ribeiro AA. Lymphatic drainage on healthy and neoplasic mammary glands in female dogs: can it really be altered? Anat Histol Embryol. 2003;32(5):282-90

27. Ran S, Volk L, Hall K, Flister MJ. Lymphangiogenesis and lymphatic metastasis in breast cancer. Pathophysiology. 2010;17 (4):229-51.

28. Maby-El Hajjami H, Petrova TV. Developmental and pathological lymphangiogenesis: from models to human disease. Histochem Cell Biol. 2008;130(6):1063-78.

29. Wick N, Saharinen P, Saharinen J, Gurnhofer E, Steiner CW, Raab I, et al. Transcriptomal comparison of human dermal lymphatic endothelial cells ex vivo and in vitro. Physiol Genomics. 2007;28(2):179-92.

30. Baluk P, Fuxe J, Hashizume H, Romano T, Lashnits E, Butz S, et al. Functionally specialized junctions between endothelial cells of lymphatic vessels. J Exp Med. 2007;204(10):2349-62.

31. Tammela T, Saaristo A, Holopainen T, Lyytikka J, Kotronen A, Pitkonen $\mathrm{M}$, et al. Therapeutic differentiation and maturation of lymphatic vessels after lymph node dissection and transplantation. Nat Med. 2007;13(12):1458-66.

32. Schmid-Schonbein GW. The second valve system in lymphatics. Lymphat Res Biol. 2003;1(1):25-9. discussion 29-31.

33. Schmid-Schonbein GW. Microlymphatics and lymph flow. Physiol Rev. 1990;70(4):987-1028.

34. Zawieja DC. Contractile physiology of lymphatics. Lymphat Res Biol. 2009;7(2):87-96.

35. Bazigou E, Xie S, Chen C, Weston A, Miura N, Sorokin L, et al. Integrin-alpha9 is required for fibronectin matrix assembly during lymphatic valve morphogenesis. Dev Cell. 2009;17 (2):175-86.

36. Quick CM, Venugopal AM, Gashev AA, Zawieja DC, Stewart RH. Intrinsic pump-conduit behavior of lymphangions. Am J Physiol Regul Integr Comp Physiol. 2007;292 (4):R1510-8.

37. Wick N, Haluza D, Gurnhofer E, Raab I, Kasimir MT, Prinz M, et al. Lymphatic precollectors contain a novel, specialized subpopulation of podoplanin(low), CCL27-expressing lymphatic endothelial cells. Am J Pathol. 2008;173(4):1202-9.

38. Baluk P, Yao LC, Feng J, Romano T, Jung SS, Schreiter JL, et al. TNF-alpha drives remodeling of blood vessels and lymphatics in sustained airway inflammation in mice. J Clin Invest. 2009;119 (10):2954-64. 
39. Kim KE, Koh YJ, Jeon BH, Jang C, Han J, Kataru RP, et al. Role of $\mathrm{CD} 11 \mathrm{~b}+$ macrophages in intraperitoneal lipopolysaccharideinduced aberrant lymphangiogenesis and lymphatic function in the diaphragm. Am J Pathol. 2009;175(4):1733-45.

40. Miteva DO, Rutkowski JM, Dixon JB, Kilarski W, Shields JD, Swartz MA. Transmural flow modulates cell and fluid transport functions of lymphatic endothelium. Circ Res. 2010;106(5):920 31.

41. Tomei AA, Siegert S, Britschgi MR, Luther SA, Swartz MA. Fluid flow regulates stromal cell organization and CCL21 expression in a tissue-engineered lymph node microenvironment. J Immunol. 2009;183(7):4273-83.

42. Shields JD, Fleury ME, Yong C, Tomei AA, Randolph GJ, Swartz MA. Autologous chemotaxis as a mechanism of tumor cell homing to lymphatics via interstitial flow and autocrine CCR7 signaling. Cancer Cell. 2007;11(6):526-38.

43. Fleury ME, Boardman KC, Swartz MA. Autologous morphogen gradients by subtle interstitial flow and matrix interactions. Biophys J. 2006;91(1):113-21.

44. Roozendaal R, Mempel TR, Pitcher LA, Gonzalez SF, Verschoor A, Mebius RE, et al. Conduits mediate transport of lowmolecular-weight antigen to lymph node follicles. Immunity. 2009;30(2):264-76.

45. Boardman KC, Swartz MA. Interstitial flow as a guide for lymphangiogenesis. Circ Res. 2003;92(7):801-8.

46. Rutkowski JM, Boardman KC, Swartz MA. Characterization of lymphangiogenesis in a model of adult skin regeneration. Am J Physiol Heart Circ Physiol. 2006;291(3):H1402-10.

47. Ng CP, Helm CL, Swartz MA. Interstitial flow differentially stimulates blood and lymphatic endothelial cell morphogenesis in vitro. Microvasc Res. 2004;68(3):258-64.

48. Helm CL, Fleury ME, Zisch AH, Boschetti F, Swartz MA. Synergy between interstitial flow and VEGF directs capillary morphogenesis in vitro through a gradient amplification mechanism. Proc Natl Acad Sci USA. 2005;102(44):15779-84.

49. Helm CL, Zisch A, Swartz MA. Engineered blood and lymphatic capillaries in 3-D VEGF-fibrin-collagen matrices with interstitial flow. Biotechnol Bioeng. 2007;96(1):167-76.

50. Rutkowski JM, Moya M, Johannes J, Goldman J, Swartz MA. Secondary lymphedema in the mouse tail: Lymphatic hyperplasia, VEGF-C upregulation, and the protective role of MMP-9. Microvasc Res. 2006;72(3):161-71.

51. Angeli V, Randolph GJ. Inflammation, lymphatic function, and dendritic cell migration. Lymphat Res Biol. 2006;4(4):217-28.

52. Lohela M, Bry M, Tammela T, Alitalo K. VEGFs and receptors involved in angiogenesis versus lymphangiogenesis. Curr Opin Cell Biol. 2009;21(2):154-65.

53. Adams RH, Alitalo K. Molecular regulation of angiogenesis and lymphangiogenesis. Nat Rev Mol Cell Biol. 2007;8(6):464-78.

54. Pytowski B, Goldman J, Persaud K, Wu Y, Witte L, Hicklin DJ, et al. Complete and specific inhibition of adult lymphatic regeneration by a novel VEGFR-3 neutralizing antibody. J Natl Cancer Inst. 2005;97(1):14-21.

55. Alitalo K, Tammela T, Petrova TV. Lymphangiogenesis in development and human disease. Nature. 2005;438(7070):946-53.

56. Bajenoff M, Germain RN. B-cell follicle development remodels the conduit system and allows soluble antigen delivery to follicular dendritic cells. Blood. 2009;114(24):4989-97.

57. Sixt M, Kanazawa N, Selg M, Samson T, Roos G, Reinhardt DP, et al. The conduit system transports soluble antigens from the afferent lymph to resident dendritic cells in the T cell area of the lymph node. Immunity. 2005;22(1):19-29.

58. Schumann K, Lammermann T, Bruckner M, Legler DF, Polleux J, Spatz JP, et al. Immobilized chemokine fields and soluble chemokine gradients cooperatively shape migration patterns of dendritic cells. Immunity. 2010;32(5):703-13.
59. Stachowiak AN, Wang Y, Huang YC, Irvine DJ. Homeostatic lymphoid chemokines synergize with adhesion ligands to trigger $\mathrm{T}$ and $\mathrm{B}$ lymphocyte chemokinesis. J Immunol. 2006;177 (4):2340-8

60. Angel CE, Chen CJ, Horlacher OC, Winkler S, John T, Browning $J$, et al. Distinctive localization of antigen-presenting cells in human lymph nodes. Blood. 2009;113(6):1257-67.

61. Mebius RE, Streeter PR, Breve J, Duijvestijn AM, Kraal G. The influence of afferent lymphatic vessel interruption on vascular addressin expression. J Cell Biol. 1991;115(1):85-95.

62. Drayton DL, Liao S, Mounzer RH, Ruddle NH. Lymphoid organ development: from ontogeny to neogenesis. Nat Immunol. 2006;7(4):344-53.

63. Mebius RE. Organogenesis of lymphoid tissues. Nat Rev Immunol. 2003;3(4):292-303.

64. Mori S, Nakano H, Aritomi K, Wang CR, Gunn MD, Kakiuchi T. Mice lacking expression of the chemokines CCL21-ser and CCL19 (plt mice) demonstrate delayed but enhanced T cell immune responses. J Exp Med. 2001;193(2):207-18.

65. Luther SA, Bidgol A, Hargreaves DC, Schmidt A, Xu Y, Paniyadi J, et al. Differing activities of homeostatic chemokines CCL19, CCL21, and CXCL12 in lymphocyte and dendritic cell recruitment and lymphoid neogenesis. J Immunol. 2002;169(1):424-33.

66. Ohl L, Henning G, Krautwald S, Lipp M, Hardtke S, Bernhardt $\mathrm{G}$, et al. Cooperating mechanisms of CXCR5 and CCR7 in development and organization of secondary lymphoid organs. J Exp Med. 2003;197(9):1199-204.

67. Mueller SN, Ahmed R. Lymphoid stroma in the initiation and control of immune responses. Immunol Rev. 2008;224:284-94.

68. Pabst O, Wahl B, Bernhardt G, Hammerschmidt SI. Mesenteric lymph node stroma cells in the generation of intestinal immune responses. J Mol Med. 2009;87(10):945-51.

69. Hammerschmidt SI, Ahrendt M, Bode U, Wahl B, Kremmer E, Forster R, et al. Stromal mesenteric lymph node cells are essential for the generation of gut-homing $\mathrm{T}$ cells in vivo. $\mathrm{J}$ Exp Med. 2008;205(11):2483-90.

70. Davalos-Misslitz AC, Rieckenberg J, Willenzon S, Worbs T, Kremmer E, Bernhardt G, et al. Generalized multi-organ autoimmunity in CCR7-deficient mice. Eur J Immunol. 2007;37(3):613-22.

71. Achtman AH, Hopken UE, Bernert C, Lipp M. CCR7-deficient mice develop atypically persistent germinal centers in response to thymus-independent type 2 antigens. J Leukoc Biol. 2009;85 (3):409-17.

72. Henning G, Ohl L, Junt T, Reiterer P, Brinkmann V, Nakano H, et al. CC chemokine receptor 7-dependent and -independent pathways for lymphocyte homing: modulation by FTY720. J Exp Med. 2001;194(12):1875-81.

73. Gunn MD, Kyuwa S, Tam C, Kakiuchi T, Matsuzawa A, Williams LT, et al. Mice lacking expression of secondary lymphoid organ chemokine have defects in lymphocyte homing and dendritic cell localization. J Exp Med. 1999;189(3):451-60.

74. Nakano H, Mori S, Yonekawa H, Nariuchi H, Matsuzawa A, Kakiuchi T. A novel mutant gene involved in T-lymphocytespecific homing into peripheral lymphoid organs on mouse chromosome 4. Blood. 1998;91(8):2886-95.

75. Stein JV, Rot A, Luo Y, Narasimhaswamy M, Nakano H, Gunn $\mathrm{MD}$, et al. The $\mathrm{CC}$ chemokine thymus-derived chemotactic agent 4 (TCA-4, secondary lymphoid tissue chemokine, 6Ckine, exodus-2) triggers lymphocyte function-associated antigen 1mediated arrest of rolling $\mathrm{T}$ lymphocytes in peripheral lymph node high endothelial venules. J Exp Med. 2000;191(1):61-76.

76. Warnock RA, Campbell JJ, Dorf ME, Matsuzawa A, McEvoy LM, Butcher EC. The role of chemokines in the microenvironmental control of T versus B cell arrest in Peyer's patch high endothelial venules. J Exp Med. 2000;191(1):77-88. 
77. Hofmann J, Greter M, Du Pasquier L, Becher B. B-cells need a proper house, whereas T-cells are happy in a cave: the dependence of lymphocytes on secondary lymphoid tissues during evolution. Trends Immunol. 2010;31(4):144-53.

78. Ochando JC, Yopp AC, Yang Y, Garin A, Li Y, Boros P, et al. Lymph node occupancy is required for the peripheral development of alloantigen-specific Foxp3+ regulatory $\mathrm{T}$ cells. J Immunol. 2005;174(11):6993-7005.

79. Menning A, Hopken UE, Siegmund K, Lipp M, Hamann A, Huehn J. Distinctive role of CCR7 in migration and functional activity of naive- and effector/memory-like Treg subsets. Eur J Immunol. 2007;37(6):1575-83.

80. Schneider MA, Meingassner JG, Lipp M, Moore HD, Rot A. CCR7 is required for the in vivo function of CD4+ CD25+ regulatory T cells. J Exp Med. 2007;204(4):735-45.

81. Zhang N, Schroppel B, Lal G, Jakubzick C, Mao X, Chen D, et al. Regulatory $\mathrm{T}$ cells sequentially migrate from inflamed tissues to draining lymph nodes to suppress the alloimmune response. Immunity. 2009;30(3):458-69.

82. Ueha S, Yoneyama H, Hontsu S, Kurachi M, Kitabatake M, Abe $\mathrm{J}$, et al. CCR 7 mediates the migration of Foxp3+ regulatory $\mathrm{T}$ cells to the paracortical areas of peripheral lymph nodes through high endothelial venules. J Leukoc Biol. 2007;82(5):1230-8.

83. Eller K, Weber T, Pruenster M, Wolf AM, Mayer G, Rosenkranz $\mathrm{AR}$, et al. CCR7 deficiency exacerbates injury in acute nephritis due to aberrant localization of regulatory $\mathrm{T}$ cells. J Am Soc Nephrol. 2010;21(1):42-52.

84. Jin Y, Chauhan SK, Saban DR, Dana R. Role of CCR7 in facilitating direct allosensitization and regulatory T-cell function in high-risk corneal transplantation. Invest Ophthalmol Vis Sci. 2010;51(2):816-21.

85. Ahrendt M, Hammerschmidt SI, Pabst O, Pabst R, Bode U. Stromal cells confer lymph node-specific properties by shaping a unique microenvironment influencing local immune responses. J Immunol. 2008;181(3):1898-907.

86. Wolvers DA, Coenen-de Roo CJ, Mebius RE, van der Cammen MJ, Tirion F, Miltenburg AM, et al. Intranasally induced immunological tolerance is determined by characteristics of the draining lymph nodes: studies with OVA and human cartilage gp-39. J Immunol. 1999;162(4):1994-8.

87. Lee JW, Epardaud M, Sun J, Becker JE, Cheng AC, Yonekura $\mathrm{AR}$, et al. Peripheral antigen display by lymph node stroma promotes T cell tolerance to intestinal self. Nat Immunol. 2007;8 (2):181-90.

88. Kyewski B, Klein L. A central role for central tolerance. Annu Rev Immunol. 2006;24:571-606.

89. Collier AY, Lee JW, Turley SJ. Self-encounters of the third kind: lymph node stroma promotes tolerance to peripheral tissue antigens. Mucosal Immunol. 2008;1(4):248-51.

90. Fletcher AL, Lukacs-Kornek V, Reynoso ED, Pinner SE, Bellemare-Pelletier A, Curry MS, et al. Lymph node fibroblastic reticular cells directly present peripheral tissue antigen under steady-state and inflammatory conditions. J Exp Med. 2010;207 (4):689-97.

91. Turley SJ, Lee JW, Dutton-Swain N, Mathis D, Benoist C. Endocrine self and gut non-self intersect in the pancreatic lymph nodes. Proc Natl Acad Sci USA. 2005;102(49):17729-33.

92. Shrestha B, Hashiguchi T, Ito T, Miura N, Takenouchi K, Oyama $\mathrm{Y}$, et al. B cell-derived vascular endothelial growth factor a promotes lymphangiogenesis and high endothelial venule expansion in lymph nodes. J Immunol. 2010;184(9):4819-26.

93. Liao S, Ruddle NH. Synchrony of high endothelial venules and lymphatic vessels revealed by immunization. J Immunol. 2006;177 (5):3369-79.

94. Vondenhoff MF, Greuter M, Goverse G, Elewaut D, Dewint P, Ware CF, et al. LTbetaR signaling induces cytokine expression and up-regulates lymphangiogenic factors in lymph node anlagen. J Immunol. 2009;182(9):5439-45.

95. Ruddle NH, Akirav EM. Secondary lymphoid organs: responding to genetic and environmental cues in ontogeny and the immune response. J Immunol. 2009;183(4):2205-12.

96. Aloisi F, Pujol-Borrell R. Lymphoid neogenesis in chronic inflammatory diseases. Nat Rev Immunol. 2006;6(3):205-17.

97. Martin AP, Coronel EC, Sano G, Chen SC, Vassileva G, CanastoChibuque $\mathrm{C}$, et al. A novel model for lymphocytic infiltration of the thyroid gland generated by transgenic expression of the CC chemokine CCL21. J Immunol. 2004;173(8):4791-8.

98. Heller F, Lindenmeyer MT, Cohen CD, Brandt U, Draganovici $\mathrm{D}$, Fischereder $\mathrm{M}$, et al. The contribution of $\mathrm{B}$ cells to renal interstitial inflammation. Am J Pathol. 2007;170(2):457-68.

99. Fan L, Reilly CR, Luo Y, Dorf ME, Lo D. Cutting edge: ectopic expression of the chemokine TCA4/SLC is sufficient to trigger lymphoid neogenesis. J Immunol. 2000;164 (8):3955-9.

100. Chen SC, Vassileva G, Kinsley D, Holzmann S, Manfra D, Wiekowski MT, et al. Ectopic expression of the murine chemokines CCL21a and CCL21b induces the formation of lymph node-like structures in pancreas, but not skin, of transgenic mice. J Immunol. 2002;168(3):1001-8.

101. Thaunat O, Kerjaschki D, Nicoletti A. Is defective lymphatic drainage a trigger for lymphoid neogenesis? Trends Immunol. 2006;27(10):441-5.

102. Flister MJ, Wilber A, Hall KL, Iwata C, Miyazono K, Nisato RE, et al. Inflammation induces lymphangiogenesis through upregulation of VEGFR-3 mediated by NF-kappaB and Prox 1 . Blood. 2009;115(2):418-29.

103. Baluk P, Tammela T, Ator E, Lyubynska N, Achen MG, Hicklin DJ, et al. Pathogenesis of persistent lymphatic vessel hyperplasia in chronic airway inflammation. J Clin Invest. 2005;115(2):247-57.

104. Watari K, Nakao S, Fotovati A, Basaki Y, Hosoi F, Bereczky B, et al. Role of macrophages in inflammatory lymphangiogenesis: enhanced production of vascular endothelial growth factor $\mathrm{C}$ and D through NF-kappaB activation. Biochem Biophys Res Commun. 2008;377(3):826-31.

105. Kajiya K, Detmar M. An important role of lymphatic vessels in the control of UVB-induced edema formation and inflammation. J Invest Dermatol. 2006;126(4):919-21.

106. Kunstfeld R, Hirakawa S, Hong YK, Schacht V, LangeAsschenfeldt B, Velasco $\mathrm{P}$, et al. Induction of cutaneous delayed-type hypersensitivity reactions in VEGF-A transgenic mice results in chronic skin inflammation associated with persistent lymphatic hyperplasia. Blood. 2004;104(4):1048-57.

107. Leong TT, Fearon U, Veale DJ. Angiogenesis in psoriasis and psoriatic arthritis: clues to disease pathogenesis. Curr Rheumatol Rep. 2005;7(4):325-9.

108. Danese S, Sans M, de la Motte C, Graziani C, West G, Phillips MH, et al. Angiogenesis as a novel component of inflammatory bowel disease pathogenesis. Gastroenterology. 2006;130(7):2060-73.

109. Schonthaler HB, Huggenberger R, Wculek SK, Detmar M, Wagner EF. Systemic anti-VEGF treatment strongly reduces skin inflammation in a mouse model of psoriasis. Proc Natl Acad Sci USA. 2009;106(50):21264-9.

110. Yao LC, Baluk P, Feng J, McDonald DM. Steroid-resistant lymphatic remodeling in chronically inflamed mouse airways. Am J Pathol. 2010;176(3):1525-41.

111. Stuht S, Gwinner W, Franz I, Schwarz A, Jonigk D, Kreipe H, et al. Lymphatic neoangiogenesis in human renal allografts: results from sequential protocol biopsies. Am J Transplant. 2007;7 (2):377-84.

112. Ling S, Qi C, Li W, Xu J, Kuang W. Crucial role of corneal lymphangiogenesis for allograft rejection in alkali-burned cornea bed. Clin Experiment Ophthalmol. 2009;37(9):874-83. 
113. Ling S, Qi C, Li W, Xu J, Kuang W. The expression of vascular endothelial growth factor $\mathrm{C}$ in transplanted corneas. Curr Eye Res. 2009;34(7):553-61.

114. Chung ES, Saban DR, Chauhan SK, Dana R. Regulation of blood vessel versus lymphatic vessel growth in the cornea. Invest Ophthalmol Vis Sci. 2009;50(4):1613-8.

115. Nathanson SD. Insights into the mechanisms of lymph node metastasis. Cancer. 2003;98(2):413-23.

116. Amioka T, Kitadai Y, Tanaka S, Haruma K, Yoshihara M, Yasui W, et al. Vascular endothelial growth factor-C expression predicts lymph node metastasis of human gastric carcinomas invading the submucosa. Eur J Cancer. 2002;38 (10):1413-9.

117. Arinaga M, Noguchi T, Takeno S, Chujo M, Miura T, Uchida Y. Clinical significance of vascular endothelial growth factor $\mathrm{C}$ and vascular endothelial growth factor receptor 3 in patients with nonsmall cell lung carcinoma. Cancer. 2003;97(2):457-64.

118. Clarijs R, Schalkwijk L, Ruiter DJ, de Waal RM. Lack of lymphangiogenesis despite coexpression of VEGF-C and its receptor Flt-4 in uveal melanoma. Invest Ophthalmol Vis Sci. 2001;42(7):1422-8.

119. Leu AJ, Berk DA, Lymboussaki A, Alitalo K, Jain RK. Absence of functional lymphatics within a murine sarcoma: a molecular and functional evaluation. Cancer Res. 2000;60(16):4324-7.

120. Padera TP, Kadambi A, di Tomaso E, Carreira CM, Brown EB, Boucher Y, et al. Lymphatic metastasis in the absence of functional intratumor lymphatics. Science. 2002;296(5574): 1883-6.

121. Issa A, Le TX, Shoushtari AN, Shields JD, Swartz MA. Vascular endothelial growth factor-C and $\mathrm{C}-\mathrm{C}$ chemokine receptor 7 in tumor cell-lymphatic cross-talk promote invasive phenotype. Cancer Res. 2009;69(1):349-57.

122. Sipos B, Kojima M, Tiemann K, Klapper W, Kruse ML, Kalthoff $\mathrm{H}$, et al. Lymphatic spread of ductal pancreatic adenocarcinoma is independent of lymphangiogenesis. J Pathol. 2005;207 (3):301-12.

123. Wong SY, Haack H, Crowley D, Barry M, Bronson RT, Hynes RO. Tumor-secreted vascular endothelial growth factor-C is necessary for prostate cancer lymphangiogenesis, but lymphangiogenesis is unnecessary for lymph node metastasis. Cancer Res. 2005;65(21):9789-98.

124. Kataru RP, Jung K, Jang C, Yang H, Schwendener RA, Baik JE, et al. Critical role of $\mathrm{CD} 11 \mathrm{~b}+$ macrophages and VEGF in inflammatory lymphangiogenesis, antigen clearance, and inflammation resolution. Blood. 2009;113(22):5650-9.

125. Jennbacken K, Vallbo C, Wang WZ, et al. Expression of vascular endothelial growth factor C (VEGF-C) and VEGF receptor-3 in human prostate cancer is associated with regional lymph node metastasis. Prostate. 2005;65(2):110-116.

126. Jenny B, Harrison JA, Baetens D, et al. Expression and localization of VEGF-C and VEGFR-3 in glioblastomas and haemangioblastomas. J Pathol. 2006;209(1):34-43.

127. Li J, Hong M, Pan T. Clinical significance of VEGF-C and VEGFR-3 expression in non-small cell lung cancer. J Huazhong Univ Sci Technolog Med Sci. 2006;26(5):587-90.

128. Filho AL, Martins A, Costa SMA, et al. VEGFR-3 expression in breast cancer tissue is not restricted to lymphatic vessels. Pathology Research and Practice. 2005;201(2):93-99.

129. Su JL, Yang PC, Shih JY, et al. The VEGF-C/Flt-4 axis promotes invasion and metastasis of cancer cells. Cancer Cell. 2006;9 (3):209-23.

130. Shields JD, Kourtis IC, Tomei AA, et al. Induction of lymphoidlike stroma and immune escape by tumors that express the chemokine CCL21. Science. 2010;328(5979):749-52.

131. Harrell MI, Iritani BM, Ruddell A. Tumor-induced sentinel lymph node lymphangiogenesis and increased lymph flow precede melanoma metastasis. Am J Pathol. 2007;170(2):774-86.

132. Ruddell RG, Knight B, Tirnitz-Parker JE, et al. Lymphotoxinbeta receptor signaling regulates hepatic stellate cell function and wound healing in a murine model of chronic liver injury. Hepatology. 2009;49(1):227-39.

133. Ruddell A, Harrell MI, Minoshima S, et al. Dynamic contrastenhanced magnetic resonance imaging of tumor-induced lymph flow. Neoplasia. 2008;10(7):706-U4.

134. Herber DL, Cao W, Nefedova Y, et al. Lipid accumulation and dendritic cell dysfunction in cancer. Nat Med. 2010;16(8):880-6. 